\title{
Optimization of the pumping station of the Milano water supply network with Genetic Algorithms
}

\author{
S. Mambretti \\ Wessex Institute of Technology, UK
}

\begin{abstract}
In the paper a method for the optimization of water distributions networks is developed and applied to the case of the water supply network of Milano. This network is very complex and has no suspended reservoirs as the hydraulic head is maintained by the action of 31 pumping stations. Starting from real data, the operations of the entire network and pumping station, with the actual scheduling, are simulated with software using EPANET engine which was developed to this purpose. Afterwards, the operation of the pumping stations is optimized through the use of a simple Genetic Algorithm, in order to reduce the energy consumption maintaining a good service. Results show a significant improvement with the new working logics, thus justifying the study. Site tests show that the assumptions made in building the model are reliable, but they will probably require some adjustments following this research.
\end{abstract}

Keywords: water distribution, Genetic Algorithms, optimization, energy saving.

\section{Introduction}

Water distribution networks are a primary part of water supply systems, and since they represent one of the main infrastructure assets of the society, its management must be effective, efficient and energy saving. To this end, hydraulic constraints are not sufficient to find the best system and economic and energy conditions also have to be taken into account. For this kind of complex and multi-objective optimization problem Evolutionary Computation may be useful. The term Evolutionary Computation (EC) [1] represents a large spectrum of heuristic approaches to simulate evolution. The latter includes: Genetic Algorithms (GAs) [2, 3], Evolutionary Strategies [4, 5], Evolutionary 
Programming [6] and Genetic Programming [7]. GAs are one of the most known $\mathrm{EC}$, because of their central use in water resources planning and management. They have been largely used in the last two decades in order to improve efficiency of water distribution systems when traditional calculus-based and enumerative optimization methods showed they were not able to cope with the geometrical complexity of these systems (a complex network of pipes, junctions and hydraulic control elements) and the water demand of customers with required quality and affordable costs. One of the first water engineering applications of GAs was related to the optimization of pump schedules for a serial liquid pipeline [8,9]. GAs have been used for least-cost design [10], and for network optimization [11-13].

Mackle et al. [14] were among the first to apply a binary GA to pumps scheduling problems, to minimize energy costs, subject to reservoir filling and emptying constrains. Then Savic and Walters [10] developed a multi-objective GA (MOGA) approach to minimize both the energy costs and the number of pump switches. The first industrial application to the pump scheduling problem was reported by Atkinson et al. [15], De Schaetzen et al. [16] and Illich and Simovic [17]. Van Zyl et al. [18] developed a hybrid optimization approach in order to reduce the excessive running times. Further improvements were provided by Prasad and Park [19], Farmani et al. [20] and Rao and Salomons [21].

In this paper, a simple GA will be applied to the water distribution network of Milano order to improve the performance of the system.

Results showed that significant improvements can be reached in terms of energy savings leading to economical benefits.

Tests on a pumping station showed that the results carried out during this research were reliable, although refinements should be considered in upcoming work.

\section{Case study: the Milano water supply network}

The water supply system of Milano [22] acquires drinking water from a number of wells; pumps convey water to reservoirs located at ground level. From those reservoirs water is pumped directly in the network, without the need for reservoirs located at higher altitude. The hydraulic head is therefore guaranteed by the pumping stations which action balances the effects of water demand.

The pipelines have a total length of $2200 \mathrm{~km}$ and in the network, there are 31 pumping stations and in each of them 3-4 pumps are installed. Each pump works with a discharge within the range 200-400 1/s and maximum head of $50 \mathrm{~m}$. Most of the pumps work with a fixed engine speed but some of them are equipped with inverters, which allow pumps working at different speeds. Currently the network is managed with traditional and empirical techniques [22], which might be not the best way. The present study aims at the verification of these conditions in order to find whether alternative and better management is possible.

The first step of the study aimed on building the model for the network in order to evaluate its behaviour and verify whether the knowledge of the system is 
sufficient for an adequate representation, if necessary, throughout the calibration of the model itself.

The available data were the geometry (topology of the network, lengths, diameters, materials, etc.), the mean daily water demand, the pumping schedule for every station, the values of pressure and discharge downstream of every station and in some other junction inside of the network.

These data have been used to build a simplified model of the water supply network with the well-known software EPANET. Simplifications consisted in the insertion in the model only for the pipes with a diameter larger than $300 \mathrm{~mm}$, neglecting the smaller ones. Such assumptions were made in order to reduce the time required for building the model and the time of simulation. However, fairly accurate reconstruction of the network was reached, which at the end consisted of 4964 junction, 96 pumps, 26 stations with an overall length of pipes equal to $460 \mathrm{~km}$.

The network has been simulated for an average day, using the daily average hourly demand curve, with a time step of 5 minutes, shown in figure 1 .

Results of the simulations have been compared with real data, recorded in the pumping stations and in some points of the network equipped with appropriate instrumentation. As can be seen (figure 2) in few hours of the day, there are significant differences (around 7:00 a.m.), but for the most of the day these differences are negligible. In figure 2 simulated and real data are compared for the "Baggio" pumping station. Data have been recorded on November $18^{\text {th }} 2009$. Simulated data showed a significant negative peak around 7.00 a.m whilst in the real network around this time, most of the pumps are turned on due to a sudden drop in pressure related to the increase in the water demand and the logic implemented in the model is probably poor and not able to follow this rapid change. Real pressures are quite steady all day long, with maximum changes smaller than $5 \mathrm{~m}$.

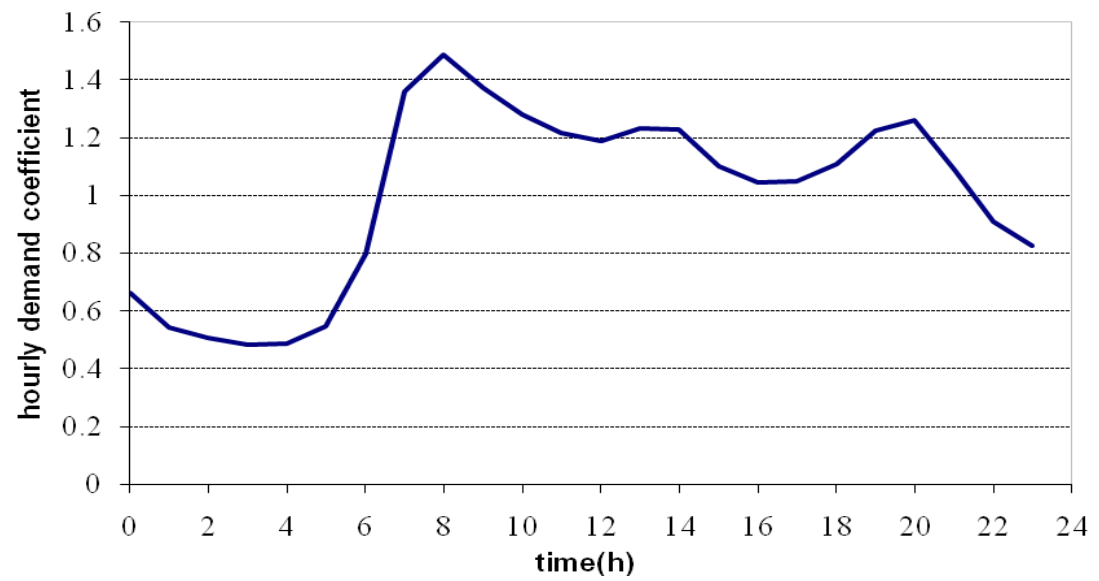

Figure 1: $\quad$ Pattern of the daily mean demand. 


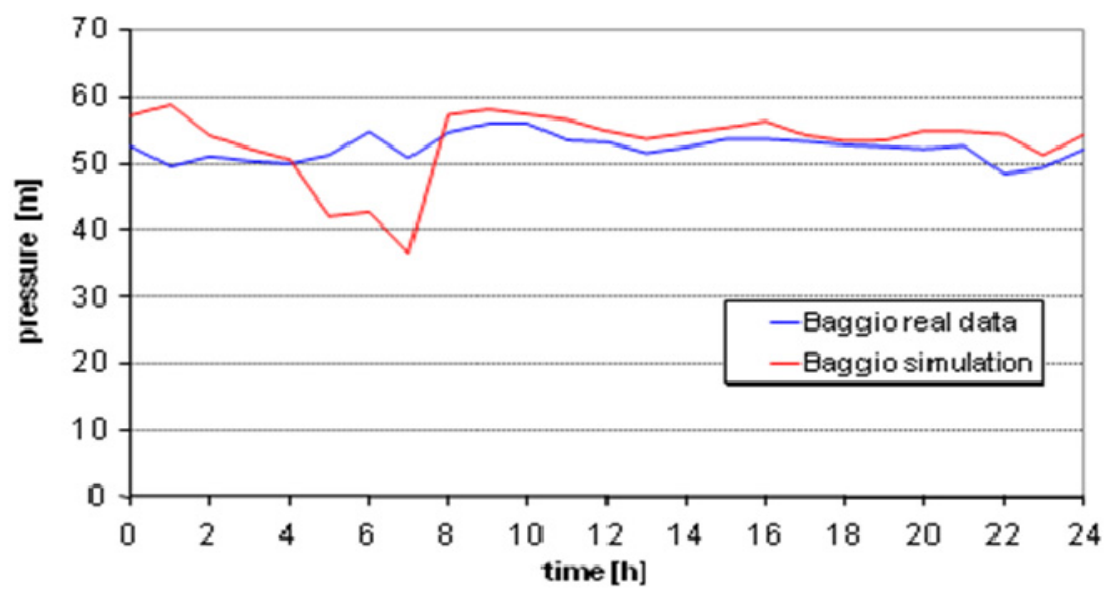

Figure 2: Recorded data $V s$ simulation in the Baggio pumping station.

Simulated pressures are normally larger than real because in the model no valves are inserted downstream the pumps, while in the real plants they are normally present.

\section{Optimization algorithm}

As the carried out results are acceptable for the purpose of the research, the following step was to find alternative scenarios able to guarantee the same level of service with the minimum energy expenditure. This is an optimization problem with constraints.

The objective function to be minimized is simply the power required by the system $W$, obtained summing the power of each running pump:

$$
W=\sum_{i=1}^{N p u m p s} \frac{\gamma \cdot H \cdot Q}{\eta}=\min
$$

where $\gamma$ is the specific weight of the fluid (water), $H$ is the head given by the pump for the discharge $Q$ and $\eta$ is the efficiency of the pump. In all simulations the efficiency has been accounted as constant in all situations and equal to 0.75 . With regard to the constraints, the imposition was that pressures must be within the range $25-75 \mathrm{~m}$; these values are checked in some "control points" located downstream the pumping stations. If the pressure in some control points falls outside the mentioned range, the value of $W$ is increased by a fixed value in order to penalize the carried out configuration.

To solve this optimization problem Genetic Algorithms have been chosen. This method is based on the mechanics of natural selection and natural genetics, 
combining survival of the fittest among string structures with a structured yet randomized information exchange to form a search algorithm. In every generation a new set of artificial "individuals" (strings) is created using bits and pieces of the old. The method is sketched in figure 3 .

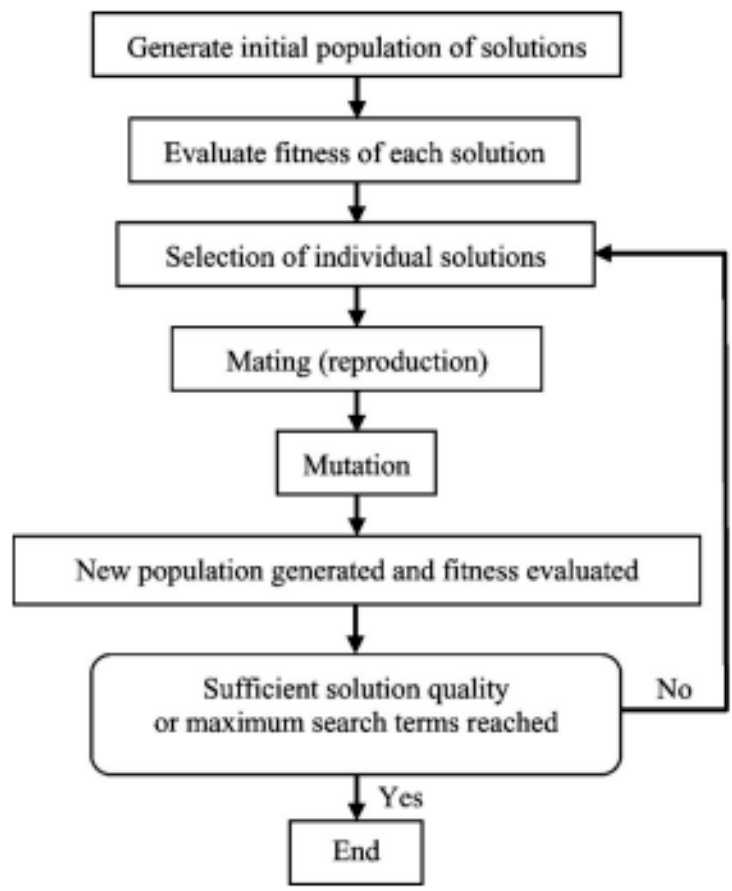

Figure 3: Generalized framework of a Genetic Algorithm.

The entire system is implemented with a binary string. Each pump is represented by 3 bits (i.e. $2^{3}=8$ possibilities) which describe its working status, i.e., pump off, pump on working at 40, 50,60, 70, 80, 90 and $100 \%$ of its nominal speed.

The first step for the implementation of the genetic algorithm is the generation of a number of configurations that will be used as the first generation of solutions ("population"). One of these is the actual configuration while the others are created randomly by the program.

Tests have been performed with different number of individuals which form the population. All the individuals that form the population are simulated and their value of $W$ is computed, which is considered the "fitness" value of each individual.

This value is then used to favour the individuals that give better results in the "reproduction" phase, i.e. the creation of a new set of individuals that form the new population. The reproduction is carried out as a simple and quasi-random crossover between two different strings. 
With regard to the initial population a variable number of individuals (within the range of 100-150) have been used; the number of iteration needed to reach the final configuration was between 100 and 200 .

Because of the partial randomness of the algorithm, each simulation may lead to a different result; therefore, for every hour of the day 8 simulation have been run, with different starting points.

\section{Results}

Results revealed a close relation between the number of initial strings and the number of iterations. However, the optimum is reached if both the initial population and the number of iterations are larger than 100. Figure 4 shows the value of $W$ for each individual together with the average for the population. The result is shown for 1:00 p.m.

As can be seen, the value of $W$ averaged on the population decreases, becoming steady after more than ten thousand runs. However, it is to be observed that this average value is not the absolute minimum, which is the actual goal of this research. Therefore, in the following steps of the research, the actual minimum for each hour has been used.

Results show the possibility of significant energy savings, both if the inverter is used or not. The required power over the day is resumed in figure 5 for the actual case and for the two optimizations (with and without inverter).

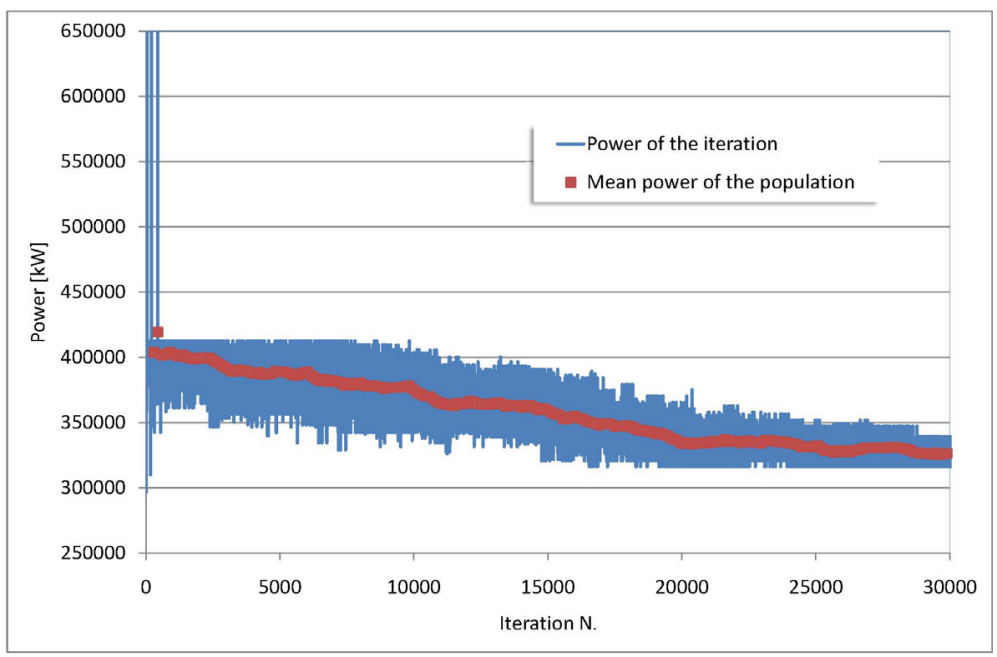

Figure 4: Power required by each individual and mean power of the populations during the search for the best configuration (200 iterations, population of 100 individuals). 


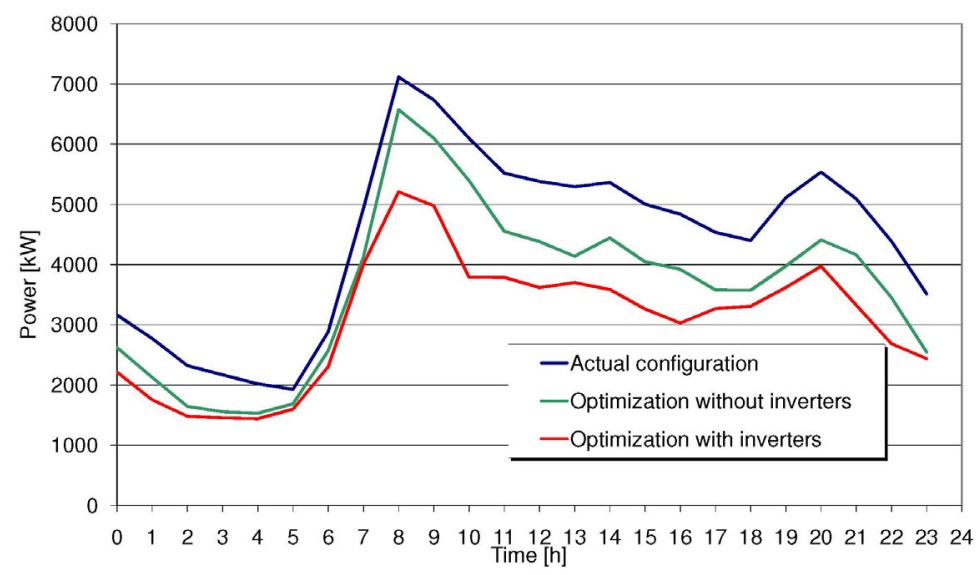

Figure 5: Required power in an average day: improvements with and without the use of inverters.

Table 1 presents a summary of results, considering the best configuration (individual) found for each hour of the day. As can be seen, it is possible to save energy up to $17.9 \%$ without inverters and up to $30.4 \%$ using inverters.

In particular, the simulations performed using inverters show the possibility of a significant improvement: the minimum saving is 17.1\% (at 5:00 a.m.) and the maximum is $38.8 \%$ (at 10:00 p.m.). Meanwhile improvements related to the system without inverters have a minimum of 7.6\% (at 8:00 a.m.) and a maximum equal to $29.2 \%$ (at 2:00 a.m.).

Moreover, it is to be noted that in all cases the speed of the pumps never decreased below $70 \%$, as in these cases the head of the pump is not sufficient to provide discharge to the network.

Finally, in order to have an idea of the possibility of economic safe, the energy cost was fixed at $0.10 € / \mathrm{kWh}$ for the whole day. Therefore, considering the actual total energy in a year equal to $38,200,000 \mathrm{kWh}$, without inverters it is

Table 1: $\quad$ Energy saved, in percentage, with and without the use of inverters for each hour of the average day.

\begin{tabular}{|c|c|c|c|c|c|c|c|c|c|c|c|c|}
\hline Hours & $\mathbf{0}$ & $\mathbf{1}$ & $\mathbf{2}$ & $\mathbf{3}$ & $\mathbf{4}$ & $\mathbf{5}$ & $\mathbf{6}$ & $\mathbf{7}$ & $\mathbf{8}$ & $\mathbf{9}$ & $\mathbf{1 0}$ & $\mathbf{1 1}$ \\
\hline $\begin{array}{c}\text { \% hourly saving } \\
\text { without inverters }\end{array}$ & 17.1 & 23.3 & 29.2 & 28.3 & 24.2 & 12.5 & 11.1 & 16.4 & 7.6 & 9.5 & 11.5 & 17.5 \\
\hline $\begin{array}{c}\text { \% hourly saving } \\
\text { with inverters }\end{array}$ & 30.0 & 36.8 & 36.3 & 33.0 & 28.7 & 17.1 & 20.2 & 18.8 & 26.8 & 26.1 & 37.8 & 31.4 \\
\hline
\end{tabular}


possible to save up to $6,840,000 \mathrm{kWh} /$ year, which means saving up to 684,000 $€$.With the use of inverters, it is possible to save up to $11,627, .000 \mathrm{kWh} /$ year, which means an economic saving equal to $1,162,700 €$.

\section{$5 \quad$ Field tests}

Field tests have been performed in one of the pumping stations in Milano. Recorded data related to one pump with the inverter are shown in figure 6 . The most important achievement to be highlighted is that, as can be seen in the figure, pumps are oversized for the need of Milano, and in fact when their speed is at a $100 \%$, the working point is positioned quite "on the right" of the curve and therefore the efficiency of the pumps falls dramatically; when the pressure in the network is low, the efficiency decreases below 60\%. Using the inverters, velocity is reduced and therefore the working point moves "to the left" and the efficiency increases.

In other words, in this case, the speed reduction raises the efficiency of the pump, and therefore it seems that the benefits in the installation of the inverters might be higher than computed.

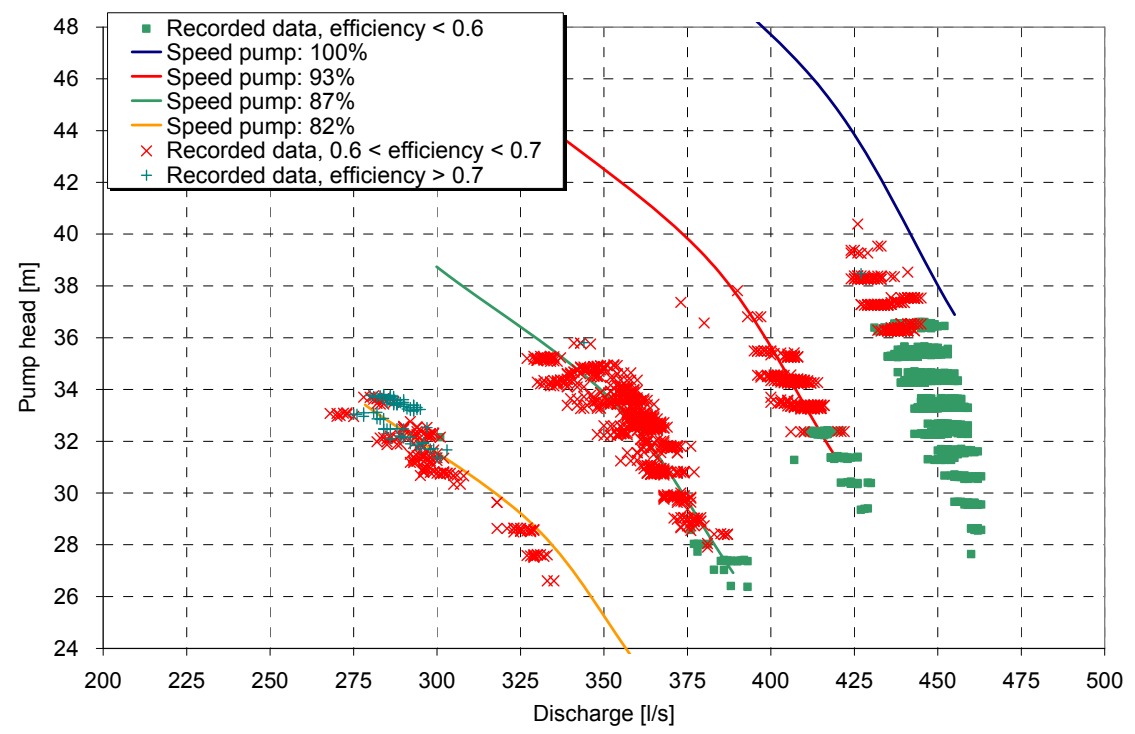

Figure 6: $\quad$ Recorded data in one of the pumping stations in Milano.

\section{Conclusions}

In the paper, the use of Genetic Algorithms has been applied to the optimization of the functioning of the pumping station of the city of Milano. To this end, the model of the water supply network has been implemented in the well-known 
software EPANET and the results of the simulations have been correlated with empirical data.

Afterwards, thousands of different pumping configurations have been tried, lead by a simple Genetic Algorithm in order to find the best configuration, i.e. the configuration which can guarantee the same actual service and the best energy savings. Configurations have been tested with and without the use of inverters, which can reduce the rotation speed of the pumps. Results show that a dramatic improvement is possible, both with and without the use of inverters. Results may require further refinements due to the simplifications adopted for the model, but they are however encouraging because of the savings that can be reached both in terms of energy and of costs (up to $6,840,000 \mathrm{kWh} /$ year equal to $684,000 €$ without inverter and $11,627,000 \mathrm{kWh} /$ year equal to $1,162.700 €$ with inverter).

Field tests showed that, because of a probable over sizing of the pumps in the Milano stations, these values could be increased if the actual efficiency was used in the mathematical model.

Further researches are needed to combine the energy savings with the different requests of a complex network as Milano's with targets that might be contradictory and therefore that require to move on the Pareto boundary.

\section{References}

[1] Back T., Fogel D.B., Michalewicz Z. (eds.) Handbook of Evolutionary Computation Institute of Physics publishing \& Oxford University Press, New York, 1997

[2] Holland J. H. Outline for a logical theory of adaptive systems. J. Assoc. Comput. Mach., 3, 297-314, 1962.

[3] Holland J. H. Adaptation in natural and artificial systems, University of Michigan Press, Ann Arbor, Mich., 1975.

[4] Rechenberg I. Evolutionstrategie: optimierung technisher systeme nach prinzipien der biologischen evolution. Frommann-Hoolzboog Verlag, 1973 (in German)

[5] Schewefel H.P. Numerical Optimization of Computer Models, John Wiley and Sons, New York, 1981

[6] Fogel L., Owens A., Walsh M. Artificial Intelligence Through Simulated Evolution, John Wiley \& Sons, Inc, New York, 1966, Koza, 1992

[7] Goldberg D.E. Genetic algorithms in search, optimization and machine learning. Addison-Wesley, Reading, Massachusetts 1989.

[8] Golberg D.E., Kuo C.H. Genetic algorithms in pipeline optimization, Journal of Computing in Civil Engineering pp. 128-141, 1(2), 1987

[9] Simpson A. R., Dandy G. C., Murphy L. J. Genetic algorithms compared to other techniques for pipe optimization. J. Water Resour. Plann. Manage., 120 (4), 423-443, 1994.

[10] Savic D.A., Walters G.A. Genetic Algorithm for Least-Cost Design of Water Distribution Networks. Journal of Water Resources Planning and Management, ASCE, 123, 67-77, 1997. 
[11] Alperovits E., Shamir U. Design of optimal water distribution systems. Water Resources Research, 13(6), 885-900, 1977.

[12] Fujiwara O., Khang D.B. A two-phase decomposition method for optimal design of looped water distribution networks. Water Resour. Res., 26(4), 539-549, 1990.

[13] Schaake J.C. Lai, D. Linear programming and dynamic programming application to water distribution network design. Rep. No. 116, Dept. of Civil Engineering, MIT, Cambridge, 1969.

[14] Mackle G., Savic D.A., Walters G. A. Application of genetic algorithms to pump scheduling for water supply. Proc. Genetic Algorithms in Engineering Systems: Innovations and Applications, GALESIA '95, IEE, London, 400-405, 1995.

[15] Atkinson R., van Zyl J.E., Walters G.A., Savic D.A. Genetic algorithm optimization of level-controlled pumping station operation. Water network modelling for optimal design and management, Centre for Water Systems, Exeter, U.K., 79-90, 2000.

[16] De Schaetzen W.B.F., Savic D.A., Waltres G.A. A Genetic Algorithm Approach to Pump Scheduling in Water Supply System. Hydroinformatics, 1998.

[17] Illich N., Simovic S.P. Evolutionary Algorithm for Minimization of Pumping Cost. Journal of Comp. in Civ. Engrg., ASCE, 12, 232-240, 1998.

[18] van Zyl, J., Savic, D. A., Walters, G.A. Operational optimization of water distribution systems using a hybrid genetic algorithm method. J. Water Resour. Plann. Manage., 130 (2), 160-170, 2004.

[19] Prasad, T. D., Park, N.S. Multiobjective genetic algorithms for design of water distribution networks. J. Water Resour. Plann. Manage., 130 (1), 7382, 2004.

[20] Farmani, R., Savic, D.A., Walters, G.A. Evolutionary multi-objective optimization in water distribution network design. Eng. Optimiz., 37(2), 167-183, 2005.

[21] Rao, Z., Salomons, E. Development of a real-time, near optimal control process for water-distribution networks. J. Hydroinform., 9 (1), 25-37, 2007.

[22] Motta V. L'acquedotto di Milano. Comune di Milano, 1989. (in Italian) 